\title{
Spin-crossover behavior and electrical conduction property in iron(II) complexes with tetrathiafulvalene moieties ${ }^{\dagger}$
}

\author{
Masayuki Nihei, ${ }^{a}$ Nobukazu Takahashi, ${ }^{a}$ Hiroyuki Nishikawa ${ }^{b}$ and Hiroki Oshio ${ }^{* a}$ \\ Received (in XXX, XXX) Xth XXXXXXXXX 200X, Accepted Xth XXXXXXXXX 200X \\ ${ }_{5}$ First published on the web Xth $X X X X X X X X X 200 X$ \\ DOI: $10.1039 / b 000000 x$
}

Iron(II) complexes with neutral and oxidized tetrathiafulvalene (TTF) moieties were prepared and X-ray crystallographic analyses, magnetic and electrical resistivity measurements 10 suggested an interaction of spin transition and electrical conductivity.

Multi-functional system, which exhibits coexistence or synergy of two different physical properties, is one of the most attractive research targets in molecule-based materials, 15 because the interplay of different physical properties may lead to novel behaviors. ${ }^{1}$ Hybrid materials, composed of magnetic and conducting moieties, have been reported to exhibit interesting multi-functionalities such as the coexistence of ferromagnetism and metallic conductivity, and field-induced 20 superconducting transitions. ${ }^{2}$ However, the switching of electrical conductivity in hybrid materials by external stimuli is still challenging. Spin-crossover $(\mathrm{SCO}){ }^{3}$ a spin transition between high-spin (HS) and low-spin (LS) states associated with relatively large structural changes, can function as a 25 switch for the electrical conductivity in hybrid systems, as electrical conductivity in molecular conductors is very sensitive to external and chemical pressures. ${ }^{4}$ A major approach employed to obtain multi-functional materials exhibiting both electrical conductivity and SCO phenomena is

30 to combine conducting anions and SCO cations in the same crystal lattice. ${ }^{5}$ This approach has recently led to an interaction of SCO and electrical conductivity being reported. ${ }^{5 a}$ An alternative approach is by the preparation of metal complexes with ligands possessing potentially 35 conducting moieties such as tetrathiafulvalene (TTF) and its derivatives. Although some metal complexes with neutral or oxidized TTF moieties have been reported, ${ }^{6}$ to the best of our knowledge, there have been no reports on the observations of both SCO and electrical conductivity in such complexes. On 40 the other hand, $\left[\mathrm{Fe}^{\mathrm{II}}(\mathrm{dpp})_{2}\right] \mathrm{X}_{2} \quad(\mathrm{dpp}=2,6$-di(pyrazol-1yl)pyridine) is one of the most studied SCO complexes, and chemical modification of the ligand, dpp, leads to different spin transition behavior. ${ }^{7}$ We report here two novel iron(II) complexes with TTF moieties, ${ }_{45}\left[\mathrm{Fe}(\mathrm{dppTTF})_{2}\right]\left(\mathrm{BPh}_{4}\right)_{2} \cdot \mathrm{MeNO}_{2} \cdot 0.5 \mathrm{Et}_{2} \mathrm{O} \quad$ (1) and $\left[\mathrm{Fe}(\mathrm{dppTTF})_{2}\right]\left[\mathrm{Ni}(\mathrm{mnt})_{2}\right]_{2}\left(\mathrm{BF}_{4}\right) \cdot \mathrm{PhCN} \quad(\mathbf{2})(\mathrm{dppTTF}=1-\{2-$ (1,3-dithiol-2ylinene)-1,3-dithiolyl $\}$-2-\{2,6-bis(1pyrazolyl)pyridyl $\}$-ethylene, $\mathrm{mnt}=$ maleonitriledithiolate). X-ray structural analyses, magnetic and electrical resistivity ${ }_{50}$ measurements suggested that $\mathbf{2}$ exhibits an interaction of SCO and electric conductivity.

The novel tridentate ligand with a TTF moiety, dppTTF, was synthesized by the Wittig reaction between formyltetrathiafulvalene and the phosphonium salt of a dpp 5 derivative (see ESI $\dagger$ ). The reaction of dppTTF with $\mathrm{Fe}\left(\mathrm{BF}_{4}\right)_{2} \cdot 6 \mathrm{H}_{2} \mathrm{O}, \quad \mathrm{Na}\left(\mathrm{BPh}_{4}\right)$ in $\mathrm{MeNO}_{2}$, followed by recrystallization from $\mathrm{MeNO}_{2} /$ diethyl ether, yielded dark purple crystals of $\mathbf{1}$.

(a)

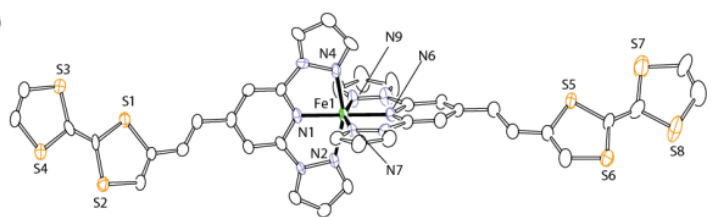

(b)
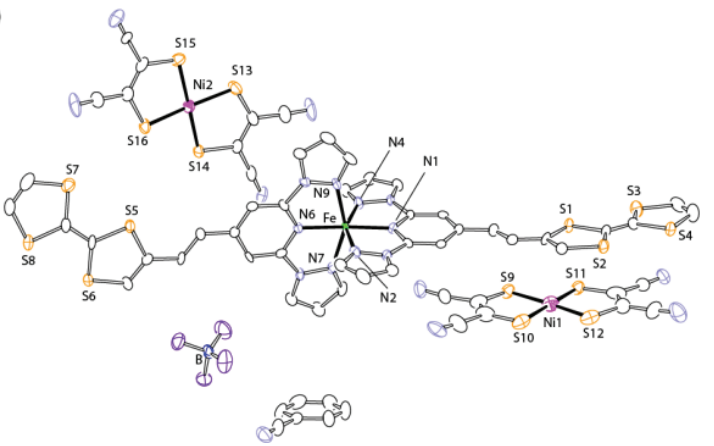

60 Fig.1. ORTEP diagrams of (a) complex cation in 1, and (b) 2 with $30 \%$ probability of thermal ellipsoids.

$\mathrm{X}$-ray structural analysis of $\mathbf{1}$ was performed at $120 \mathrm{~K}$, and an ORTEP diagram of the complex cation is depicted in Fig. 1a. 1 crystallized in the monoclinic space group $P 2_{1} / c$ and the ${ }_{65}$ asymmetric unit contains a complex cation and two $\mathrm{BPh}_{4}^{-}$ anions. In the complex cation of $\mathbf{1}$, two tridentate coordination sites in dppTTFs coordinate to an iron(II) ion and two peripheral TTF moieties are linked to the central core via ethylene bridges. The iron(II) ion has a distorted 70 octahedral coordination structure with six nitrogen atoms from the two tridentate dppTTF ligands. The Fe-N bond lengths are in the range of $1.914(6)-2.006(7) \AA$, characteristic of LS iron(II) ions. Distortion of the coordination geometry from the ideal octahedron was quantified by using $\Sigma$ parameters $75\left(=\Sigma|90-\theta|\left(^{\circ}\right)\right.$, where the $\theta$ value is the bite angle of the two coordinated ligands). ${ }^{8}$ The $\Sigma$ value of $89.7^{\circ}$ for the central iron(II) ion in $\mathbf{1}$ affirms that the iron(II) ion is in the LS state. The complex cation has two crystallographically independent TTF moieties. The central $\mathrm{C}=\mathrm{C}$ bond lengths in TTF 80 derivatives are sensitive to the oxidation state, and oxidized species have longer $\mathrm{C}=\mathrm{C}$ bonds than that in neutral species. ${ }^{6}$ In 1, the central $\mathrm{C}=\mathrm{C}$ bond lenghts are 1.34(1) and 1.33(1) $\AA$ 
for C16-C17 and C35-C36, respectively, which are typical values for neutral TTF derivatives. In 1, the shortest intermolecular $\mathrm{S} \cdots \mathrm{S}$ contact between TTF moieties was 3.722(4) $\AA$, suggesting no significant intermolecular 5 interactions between TTFs. X-ray structural analysis at higher temperature could not be done as the crystals were unstable due to solvent loss.

Magnetic susceptibility measurements for $\mathbf{1}$ were performed in the temperature range of $5-300 \mathrm{~K}$ (Fig. S1 $\dagger$ ).

10 The $\chi_{\mathrm{m}} T$ value was $2.79 \mathrm{emu} \mathrm{mol}^{-1} \mathrm{~K}$ at $300 \mathrm{~K}$, which is close to the Curie constant $\left(3.00 \mathrm{emu} \mathrm{mol}^{-1} \mathrm{~K}\right.$ with $\left.g=2\right)$ for HS iron(II) ions. As the temperature was lowered, the $\chi_{\mathrm{m}} T$ values showed gradual decrease centered at ca. $200 \mathrm{~K}$, and reached the minimum value of $0.15 \mathrm{emu} \mathrm{mol}^{-1} \mathrm{~K}$ at $5 \mathrm{~K}$, suggesting the 15 occurrence of gradual SCO to the diamagnetic LS state in the iron(II) ions.

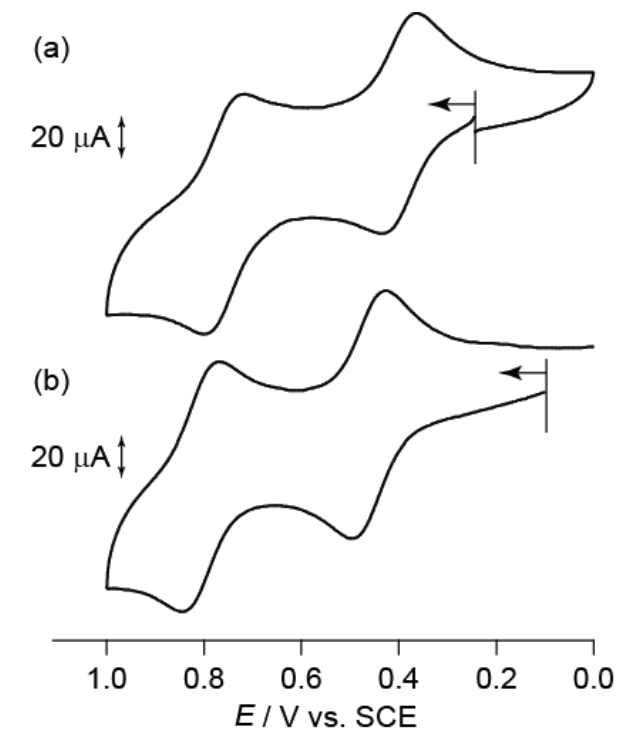

Fig. 2. Cyclic voltammograms for (a) dppTTF and (b) 1.

Cyclic voltammograms of dppTTF and $\mathbf{1}$ in $\mathrm{MeCN}$ are ${ }_{20}$ displayed in Fig. 2. The dppTTF showed two reversible oxidation waves at 0.40 and $0.76 \mathrm{~V}$ vs. SCE (Fig. 3a), which is close to the redox potentials of TTF $(0.38$ and $0.77 \mathrm{~V}$ vs. SCE). ${ }^{9}$ The two oxidation waves are, therefore, assignable to the two-stepped one-electron oxidation process in TTF moiety ${ }_{25}\left(\mathrm{dppTTF} / \mathrm{dppTTF}^{+\bullet} / \mathrm{dppTTF}^{2+}\right)$. In $\mathbf{1}$, three quasi-reversible oxidation waves were observed at $0.46,0.81$ and $1.26 \mathrm{~V}$ (Fig. $3 \mathrm{~b}$ and Fig. S2 $\dagger$ ). The first two oxidation waves correspond to two-electron oxidation of the TTF moieties, and the third wave is assignable to the $\mathrm{Fe}(\mathrm{II}) / \mathrm{Fe}$ (III) couple. The positive 30 shift of the oxidation potentials of TTF moieties in 1 compared with that in dppTTF is due to the electron withdrawing effect of the iron(II) center as observed in other metal complexes with TTF moieties. ${ }^{6}$ The quasi-reversible oxidation behavior of TTF moieties and the higher oxidation 35 potential of the central iron(II) ion in $\mathbf{1}$ suggested that the oxidized species composed of $\mathrm{TTF}^{+\bullet}$ radicals and the iron(II) ion are relatively stable at room temperature.

Galvanostatic $(I=5 \mu \mathrm{A})$ oxidation of $\left[\mathrm{Fe}(\mathrm{dppTTF})_{2}\right]^{2+}$ with $\left(\mathrm{Bu}_{4} \mathrm{~N}\right)\left[\mathrm{Ni}(\mathrm{mnt})_{2}\right]$ and $\left(\mathrm{Bu}_{4} \mathrm{~N}\right) \mathrm{BF}_{4}$ in $\mathrm{PhCN}$ under nitrogen 40 atomosphere gave dark brown crystals of 2 (Fig. 1b). X-ray structural analyses of 2 were performed at 200 and 300 K. 2 crystallized in the triclinic space group $P \overline{1}$, and the asymmetric unit is composed of one complex cation, two $\left[\mathrm{Ni}(\mathrm{mnt})_{2}\right]^{-}$anions ([Ni1] and $\left.[\mathrm{Ni} 2]^{-}\right)$, and one $\mathrm{PhCN}$ 45 molecule (Fig. 1b and Fig. S3 $\uparrow$ ). In the complex cation, the iron(II) ion has an average coordination bond length of $2.106(6) \AA$ and the $\Sigma$ value of $133.9^{\circ}$ at $300 \mathrm{~K}$. The structural feature clearly revealed that the electronic state of the iron ion is HS iron(II). [Ni1] $]^{-}$and $\left[\mathrm{Ni}_{2}\right]^{-}$have square planar structures 50 with the average coordination bond lengths of Nil-S = 2.166(3) $\AA$ and Ni2-S = 2.141(3) $\AA$, respectively, which are typical values for $\left[\mathrm{Ni}(\mathrm{mnt})_{2}\right]^{-}$anions. ${ }^{10}$ Charge considerations and structural features of each constituent unit suggest that the complex cation has +3 charge. The complex cation in $\mathbf{2}$ has 55 two TTF moieties, TTF1 and TTF2, with S1 - S4 and S5 - S8 atoms, respectively. The central $\mathrm{C}=\mathrm{C}$ bond lengths are 1.38(1) $\AA$ both in TTF1 and TTF2, and the apparently longer $\mathrm{C}=\mathrm{C}$ bond than that in $\mathbf{1}$ suggested that the oxidation states of TTF 1 and TTF2 are either a mixed-valent state composed of $60 \mathrm{TTF}^{+\bullet}$ and $\mathrm{TTF}^{0}$, or an averaged oxidation state of $\mathrm{TTF}^{0.5+}$. In 2 , the TTF moieties and $\left[\mathrm{Ni}(\mathrm{mnt})_{2}\right]^{-}$anions form 2-D layers on a $a b$ plane and the layers are linked through the $\left[\mathrm{Fe}(\mathrm{dppTTF})_{2}\right]^{3+}$, where TTF and dpp are bridged by ethylene groups (Fig. S3 and $\mathrm{S} 4 \dagger$ ). The $\left[\mathrm{Ni}^{-}\right]^{-}$moieties are strongly ${ }_{65}$ dimerized with an interplane distance of $3.460 \AA$. The [Ni1] dimers and weakly dimerized TTF1 moieties form 1-D columnar structures with a [TTF1]-[TTF1]-[Ni1]-[Ni1] repeating unit. On the other hand, weakly dimerized TTF2 and $[\mathrm{Ni2}]^{-}$moieties are aligned perpendicular to the [TTF1]-

70 [Ni1] columns with short $\mathrm{S} \cdots \mathrm{S}$ contacts, forming herringbonelike 2-D layers. In the layers each constituent unit interacts with $\mathrm{S} \cdots \mathrm{S}$ contacts in the range of 3.402-3.671 $\AA$ (Table $\mathrm{S} 1 \dagger$ ). As the temperature was lowered, significant structural changes were observed at $200 \mathrm{~K}$ while the space group 75 remained unchanged. The average coordination bond length and the $\Sigma$ value are $2.05(1) \AA$ and $115.9^{\circ}$, respectively, suggesting the occurrence of SCO from the HS to the LS state. It should be noted that the $\mathrm{S}^{\cdots} \mathrm{S}$ distances between TTF and $\left[\mathrm{Ni}(\mathrm{mnt})_{2}\right]^{-}$anions in the 2-D layers were significantly 80 changed and the dimerized constituent units became closer with the structural changes in the iron(II) centers (Table S1†).

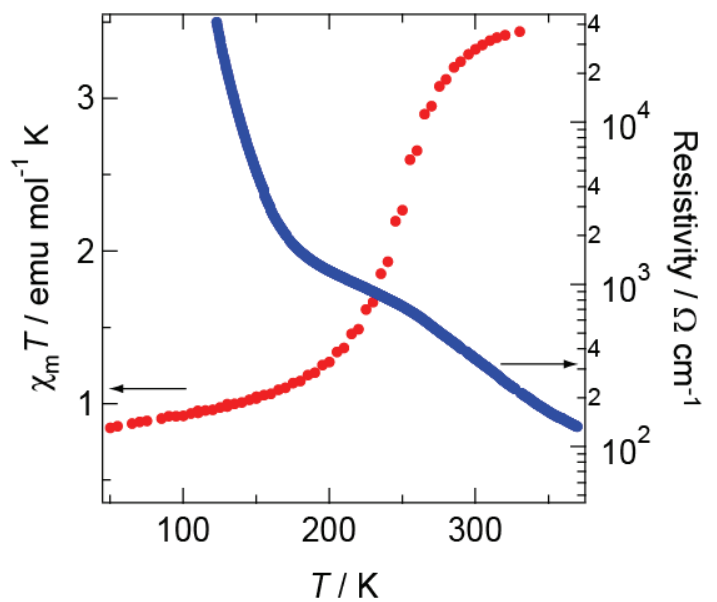

Fig. 3. Temperature dependence of $\chi_{\mathrm{m}} T$ values and resistivity in $\mathbf{2}$ 
In the magnetic susceptibility measurements for 2 , the $\chi_{\mathrm{m}} T$ values showed gradual change associated with the SCO of the

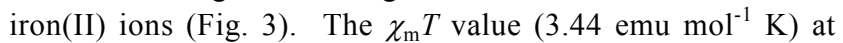
$330 \mathrm{~K}$ corresponds to the theoretical value $\left(3.75 \mathrm{emu} \mathrm{mol}^{-1} \mathrm{~K}\right)$ 5 for the one isolated HS iron(II) ion and two isolated $S=1 / 2$ radicals, suggesting that the TTF and $\left[\mathrm{Ni}^{-}\right]^{-}$moieties are paramagnetic and the strongly dimerized $\left[\mathrm{Ni}^{-}\right]^{-}$moieties are in the singlet state, even at $330 \mathrm{~K}$. The $\chi_{\mathrm{m}} T$ value is $0.80 \mathrm{emu}$ $\mathrm{mol}^{-1} \mathrm{~K}$ at $35 \mathrm{~K}$, corresponding to the expected value $(0.75$ $10 \mathrm{emu} \mathrm{mol}^{-1} \mathrm{~K}$ ) for one LS iron(II) ions and two magnetically isolated radicals. The sudden decrease of $\chi_{\mathrm{m}} T$ values below $25 \mathrm{~K}$ is attributed to antiferomagnetic interactions between radicals (Fig. S5 $\dagger$ ). It should be noted that the spin transition gradually occurred in the temperature range of $170-300 \mathrm{~K}$.

15 The temperature dependence of electrical resistivity was measured on a single crystal of $\mathbf{2}$ by the four-probe dc method (Fig. 3). The resistivities of $\mathbf{2}$ along crystallographic $c$ axis showed semiconducting behavior above $280 \mathrm{~K}$ and the conductivity at room temperature was estimated to be $2.6 \times$ $2010^{-3} \mathrm{~S} \mathrm{~cm}^{-1}$. Although the conducting pathway in 2 is not clear, the herringbone-like 2-D structure along $b c$ plane might be responsible for the semiconducting behavior. As the temperature was lowered, an anomaly was observed in the temperature range of $160-280 \mathrm{~K}$, which corresponds well to 25 the temperature range for the spin transition of iron centers. The activation energy below and above the anomaly were 129 $\mathrm{meV}(126-160 \mathrm{~K})$ and $119 \mathrm{meV}(280-360 \mathrm{~K})$, respectively. 2 shows SCO with relatively large structural modification depending on the temperatures, and the modulation of the 30 electric conductivity might be, therefore, ascribable to the chemical pressure induced by SCO in the iron(II) core.

In summary, the novel iron(II) complexes with TTF moieties linked by ethylene bonds were presented. 1 showed reversible redox behavior and thermal SCO. The 35 galvanostatic oxidation of $\left[\mathrm{Fe}(\mathrm{dppTTF})_{2}\right]^{2+}$ with $\left[\mathrm{Ni}(\mathrm{mnt})_{2}\right]^{-}$ anions yielded the oxidized complex 2. Magnetic and resistivity measurements suggested that $\mathbf{2}$ showed an interaction of spin transition and conducting behavior. Detailed variable temperature structural analyses and 40 photomagnetic experiments are currently underway to clarify the mechanism of conductivity and to explore the switching of conductivity by light irradiation.

\section{Acknowledgement}

This work was supported by a Grant-in-Aid for Scientific ${ }_{45}$ Research on Innovative Areas ("Coordination Programming" Area 2107, No. 21108006) from MEXT, Japan, and the Kurata Memorial Hitachi Science and Technology Foundation.

\section{Notes and references}

${ }^{a}$ Graduate School of Pure and Applied Sciences, University of Tsukuba, 50 Tennodai 1-1-1, Tsukuba, Ibaraki, Japan. Fax: +81-29-853-4238; Tel: +81-29-853-4238; E-mail: oshio@chem.tsukuba.ac.jp

${ }^{b}$ College of Science, Ibaraki University, Bunkyo 2-1-1, Mito, Ibaraki, Japan. Fax: +81-29-228-8371; Tel:+81-29-228-8371; E-mail: nisikawa@mx.ibaraki.ac.jp

$55 \dagger$ Electronic Supplementary Information (ESI) available: Additional figures and experimental procedure. See DOI: 10.1039/b000000x/
+ Synthesis of 1 : The reaction of $\mathrm{Fe}\left(\mathrm{BF}_{4}\right)_{2} \cdot 6 \mathrm{H}_{2} \mathrm{O}(8 \mathrm{mg}, 0.022 \mathrm{mmol})$ with dppTTF $(20 \mathrm{mg}, 0.045 \mathrm{mmol})$ in $\mathrm{MeNO}_{2}(5 \mathrm{~mL})$ gave a dark purple solution. $\mathrm{Na}\left(\mathrm{BPh}_{4}\right)(80 \mathrm{mg}, 0.23 \mathrm{mmol})$ was added to the reaction 60 mixture, and the resulting solution was filtered. Dark purple crystals of $\mathbf{1}$ were obtained by slow diffusion of dietyl ether into the filtrate. Anal. Calcd. for dried $1\left(\mathrm{C}_{87} \mathrm{H}_{69} \mathrm{~B}_{2} \mathrm{Fe}_{1} \mathrm{~N}_{11} \mathrm{O}_{2} \mathrm{~S}_{8}\right): \mathrm{C}, 62.55 ; \mathrm{H}, 4.40 ; \mathrm{N}, 9.22 \%$. Found: C, 62.47; H, 4.28; N, 9.14\%.

Synthesis of 2: The reaction of $\mathrm{Fe}\left(\mathrm{BF}_{4}\right)_{2} \cdot 6 \mathrm{H}_{2} \mathrm{O}(8 \mathrm{mg}, 0.022 \mathrm{mmol})$ with 65 dppTTF (20 mg, $0.045 \mathrm{mmol})$ in $\mathrm{PhCN}(14 \mathrm{~mL})$ gave a dark purple solution. $\left(\mathrm{Bu}_{4} \mathrm{~N}\right)\left[\mathrm{Ni}(\mathrm{mnt})_{2}\right](40 \mathrm{mg}, 0.07 \mathrm{mmol})$ and $\left(\mathrm{Bu}_{4} \mathrm{~N}\right) \mathrm{BF}_{4}(147 \mathrm{mg}$, $0.45 \mathrm{mmol})$ were added to the reaction mixture, and galvanostatic oxidation $(I=5 \mu \mathrm{A})$ of the resulting solution gave dark brown crystals of 2. Anal. Calcd. for $\mathrm{C}_{61} \mathrm{H}_{35} \mathrm{~B}_{1} \mathrm{Fe}_{1} \mathrm{~N}_{19} \mathrm{Ni}_{2} \mathrm{O}_{2} \mathrm{~S}_{16}: \mathrm{C}, 39.84 ; \mathrm{H}, 1.92 ; \mathrm{N}$, $7014.47 \%$. Found: C, 40.10; H, 1.95; N, 14.18\%.

Crystal data for 1 at $120 \mathrm{~K}: \mathrm{C}_{89} \mathrm{H}_{74} \mathrm{~B}_{2} \mathrm{Fe}_{1} \mathrm{~N}_{11} \mathrm{O}_{25} \mathrm{~S}_{8}$, monoclinic $P 2{ }_{1} / c, a=$ 21.330(2) $\AA, b=22.146(2) \AA, c=17.307(2) \AA, \beta=95.123(2)^{\circ}, V=$ 8143(1) $\AA^{3}, Z=4, d_{\text {calcd. }}=1.364 \mathrm{Mg} \mathrm{m}^{-3}, 45908$ reflections measured, 15968 unique reflections $\left(R_{\text {int }}=0.1533\right)$. Final $R 1=0.1026$ and $w R 2=$ $750.2129(I>2 \sigma I)$. Crystal data for 2 at $200 \mathrm{~K}: \mathrm{C}_{61} \mathrm{H}_{31} \mathrm{~B}_{1} \mathrm{~F}_{4} \mathrm{Fe}_{1} \mathrm{~N}_{19} \mathrm{Ni}_{2} \mathrm{~S}_{16}$, triclinic $P \overline{1}, a=13.688(2) \AA, b=14.900(2) \AA, c=18.364(2) \AA, \alpha=$ $89.572(3)^{\circ}, \beta=83.176(3)^{\circ}, \gamma=74.454(3)^{\circ}, V=3581.9(7) \AA^{3}, Z=2, d_{\text {calcd. }}$. $=1.672 \mathrm{Mg} \mathrm{m}^{-3}, 16246$ reflections measured, 10251 unique reflections $\left(R_{\text {int }}=0.0629\right)$. Final $R 1=0.0874$ and $w R 2=0.2084(I>2 \sigma I)$. at $300 \mathrm{~K}$ : 80 triclinic $P \overline{1}, a=13.828(2) \AA, b=15.156(2) \AA, c=18.255(3) \AA, \alpha=$ $89.722(2)^{\circ}, \beta=83.344(2)^{\circ}, \gamma=74.195(2)^{\circ}, V=3654.8(9) \AA^{3}, Z=2, d_{\text {calcd. }}$. $=1.638 \mathrm{Mg} \mathrm{m}^{-3}, 14934$ reflections measured, 10226 unique reflections $\left(R_{\text {int }}=0.0198\right)$. Final $R 1=0.0779$ and $w R 2=0.2198(I>2 \sigma l)$.

1 (a) E. Coronado and P. Day, Chem. Rev., 2004, 104, 5449; (b) E.

85 Coronado and E. Coronado, J. R. Galán-Mascarós, J. Mater. Chem., 2005, 15, 66; (c) L. Ouahab, Chem. Mater., 1997, 9, 1909; (d) H. Hiraga, H. Miyasaka, K. Nakata, T. Kajiwara, S. Takaishi, Y. Oshima, H. Nojiri and M. Yamashita, Inorg. Chem., 2007, 46, 9661; (e) A. Kobayashi, E. Fujiwara and H. Kobayashi, Chem. Rev., 2004, 104, 5243; (f) L. Ouahab and T. Enoki, Eur. J. Inorg. Chem., 2004, 933.

2 (a) E. Coronado, J. R. Galán-Mascarós, C. J. Comez-García, V. N. Laukhin, Nature, 2000, 408, 447; (b) S. Uji, H. Shinagawa, T. Terashima, T. Yakabe, Y. Terai, M. Tokumoto, A. Kobayashi, H. Tanaka and H. Kobayashi, Nature, 2001, 410, 908.

953 P. Gütlich and H. A. Goodwin (Eds.), Spin Crossover in Transition Metal Compounds I-III; Springer: New York, 2004m Topics in Current Chemistry 233-235.

4 (a) K. Murata, S. Kagoshima, S. Yasuzuka, H. Yoshino and R. Kondo, J. Phys. Soc. Jpn., 2006, 75, 051015; (b) S. Hünig, K. Sinzger, M. Jopp, D. Bauer, W. Bietsch, J. U. von Schütz and H. C. Wolf, Angew. Chem. Int. Ed., 1992, 31, 859; (c) S. Aonuma, H. Sawa, R. Kato and H. Kobayashi, Chem. Lett., 1993, 513.

5 (a) K. Takahashi, H.-B. Cui, Y. Okano, H. Kobayashi, H. Mori, H. Tajima, Y. Einaga and O. Sato, J. Am. Chem. Soc., 2008, 130, 6688; (b) S. Dorbes, L. Lalade, J. A. Real and C. Faulmann, Chem. Commun, 2005, 69; (c) C. Faulmann, S. Dorbes, B. G. Bonneval, G. Molnár, A. Bousseksou, C. J. Comez-García, E. Coronado and L. Valade, Eur. J. Inorg. Chem., 2005, 3261; (d) C. Faulmann, K. Jacob, S. Dorbes, S. Lampert, I. Malfant, M.-L. Doublet, L. Valade and J. A. Real, Inorg. Chem. 2007, 46, 8548; (e) L. C. J. Pereira, A. M. Gulamhussen, J. C. Dias, I. C. Santos and M. Almeida, Inorg. Chim. Acta., 2007, 360, 3887.

6 (a) K. Hervé, S.-X. Liu, O. Cador, S. Golhen, Y. Le Gal, A. Bousseksou, H. Stoeckli-Evans, S. Decurtins and L. Ouahab, Eur. J. Inorg. Chem., 2006, 3498; (b) B. W. Smucker and K. R. Dunbar, J. Chem. Soc., Dalton Trans., 2000, 1309; (c) T. Devic, D. Rondeau, Y. Sahin, E. Levillain, R. Clérac, P. Batail and N. Avarvari, Dalton Trans., 2006, 1331; (d) W. Lu, Y. Zhang, J. Dai, Q.-Y. Zhu, G.-Q. Bian and D.-Q. Zhang, Eur. J. Inorg. Chem., 2006, 1629: (e) S. Ichikawa, S. Kimura, K. Takahashi, H. Mori, G. Yoshida, Y. Manabe, M. Matsuda, H. Tajima and J. Yamaura, Inorg. Chem., 47, 4140; (f) S.-X. Liu, C. Ambrus, S. Dolder, A. Neels and S. Decurtins, Inorg. Chem., 2006. 45, 9622; (g) N. Avarvari and M. Fourmigué, Chem. Commun., 2004, 1300; (h) F. Pointillart, T. Cauchy, Y. Le Gai, S. Golhen, O. Cador and L. Ouahab, Inorg. Chem., 2010, 49, 1947; (i) F. Setili, L. Ouahab, S. Golhen, Y. Yoshida and G. Saito, Inorg. Chem., 42, 1791; (j) V. Martínez, A. B. Gaspar, M. C. Muñoz, R. Ballesteros, 
N. Ortega-Villar, V. M. Ugalde-Saldívar, R. Moreno-Esparza and J. A. Real, Eur. J. Inorg. Chem., 2009, 303.

7 (a) C. Carbonera, J. S. Costa, V. A. Money, J. Elhaïk, J. A. K. Howard, M. A. Halcrow and J.-F. Létard, Dalton Trans., 2006, 3058; (b) M. A. Halcrow, Coord. Chem. Rev., 2005, 249, 2880; (c) M. Nihei, L. Han and H. Oshio, J. Am. Chem. Soc., 2007, 129, 5312; (d) C. Rajadurai, F. Schramm, O. Fuhr and M. Ruben, Eur. J. Inorg. Chem., 2008, 2649.

8 P. Guionneau, M. Marchivie, G. Bravic, J.-F. Létard, D. Chasseau, J. Mater. Chem., 2002, 12, 2546.

9 R. Adnreu, I. Malfant, P. G. Lacroix and P. Cassoux, Eur. J. Org. Chem., 2000, 737.

10 E. Ribera, C. Rovira, J. Veciana, J. Tarrés, E. Canadell, R. Rousseau, E. Molins, M. Mas, J.-P. Schoeffel, J.-P. Pouget, J. Morgado, R. T.

15 Henriques and M. Almeida, Chem. Eur. J. 1999, 5, 2025. 